\title{
Aspirin induced intraoral burn: A rare case report with emphasis on its diagnosis
}

\author{
Amita Poswal ${ }^{1, *}$, Harsha Jain ${ }^{2}$, Balram Garg ${ }^{3}$, Pradeep Sharma ${ }^{4}$ \\ ${ }^{1}$ Senior Resident, ${ }^{2}$ Professor, ${ }^{3}$ Reader, ${ }^{4}$ Senior Lecturer, ${ }^{1}$ Dept. of Dentistry, ${ }^{2-4}$ Dept. of Oral and Maxillofacial Surgery, ${ }^{1}$ UCMS \\ \& GTB Hospital Dilshad Garden, New Delhi, ${ }^{2-4}$ I T S Dental College Muradnagar, Ghaziabad Uttar Pradesh, India \\ *Corresponding Author: \\ Email: poswal.dramita152@gmail.com
}

\begin{abstract}
Introduction: We present a case of chemical burn due to use of aspirin for pain control as self-medication. A patient placed Aspirin tablet in the right posterior lingual vestibule. A diagnosis of chemical burn was made based on history and clinical examination. Patient was advised to discontinue the habit and self- medication and was treated symptomatically.
\end{abstract}

Keywords: Chemical burn, Aspirin, Recreational drugs.

\section{Introduction}

Oral ulceration has many potential causes ranging from physical trauma to malignancy. ${ }^{1}$ Most traumatic ulceration reflects local physical etiologies such as a broken tooth, a dental restoration or trauma from an orthodontic or prosthodontic appliance. Chemicals are a less common cause of traumatic ulceration. Examples include local application of medications (eg aspirin), recreational drugs (cocaine) or some materials commonly used by dentists and non-pharmaceutical substances. $^{2,3}$

\section{Case Report}

A thirty five years old female patient reported to the Department of Oral and Maxillofacial Surgery, ITS - CDSR, Ghaziabad with chief complaint of painful ulcer in mouth since one day. She gave the history of toothache for which she placed aspirin powder below the tongue after which she developed the ulcer, which was painful. On local examination there was sloughing of oral mucosa on ventral aspect of tongue for approximately $3 \times 4 \mathrm{cms}$ (Fig. 1) and associated with whitish slough on buccal mucosa (Fig. 2) correlating with diagnosis of Aspirin burn. We prescribed her topical steroid and anesthetic application (Kenacort $0.1 \%$ and Dologel CT) along with multivitamin preparation and she responded well.

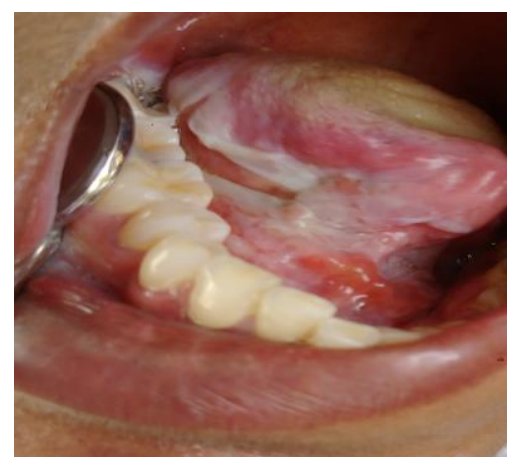

Fig. 1: Clinical photograph showing sloughing and erythema on ventral aspect of tongue right side

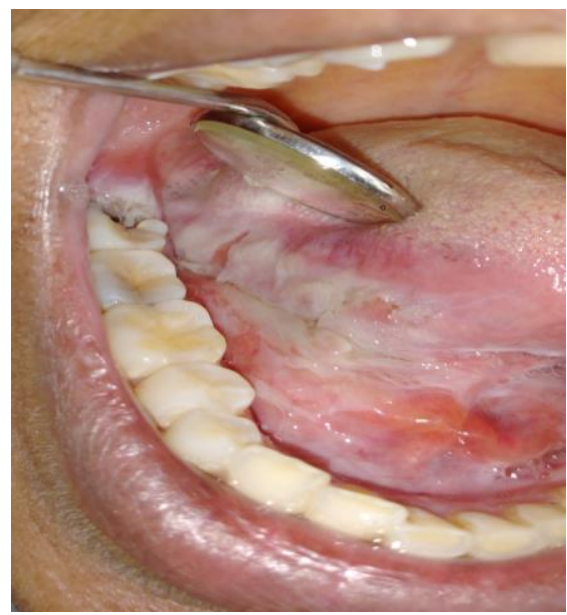

Fig. 2: clinical photograph after one week showing partial healing of ulcer

\section{Discussion}

Chemical burn of oral mucosa is a rare occurring phenomena. It can be classified as accidental, selfinflicted and others ${ }^{4}$ self-inflicted chemical burn had been reported in literature including use of aspirin induced chemical burn. It is due to improper use of medication by the patient. Aspirin is highly acidic in nature (low PH 3.5-5.0) and hence result in coagulative necrosis of mucosa which looks like a mucosal burn called as "Aspirin burns'. The intensity of tissue damage is directly related to caustic nature of agent, quantity and duration of exposure. Chemically induced oral ulceration can affect any oral mucosal site but the most often affected sites are the labial and buccal mucosae where the patient commonly place the medication. Clinical findings include dull continuous pain with burning sensation. There is erythema and edema of the oral mucosa and gingiva which leads to the formation of white slough (pseudo-membrane) covering the underlying ulceration as seen in our case (Fig. 1). In some cases the ulceration has an irregular border and bleeds easily. In advance cases if there is 
involvement of the ductal openings of the major salivary glands, transient obstructive sialadenitis may lead to permanent obstruction, chronic sialadenitis which requires surgical excision of the gland. ${ }^{5,6}$ In instances of prolonged contact, some agents can be absorbed and may cause systemic effects. ${ }^{7}$

Diagnosis of chemically induced oral ulceration is based upon clinical history and clinical features. A history demonstrating chronological correspondence between a potential causative agent and the onset of the ulceration greatly aids diagnosis.

Histopathological examination of lesional and perilesional tissue is rarely indicated unless it is difficult to obtain an adequate history or if there is a suspicion of malignancy or potential malignancy. ${ }^{8}$ The histopathology of chemically induced ulceration typically demonstrates areas of focal coagulative necrosis of the epithelium, ulceration, intra- and extracellular oedema and a sub-epithelial acute inflammatory infiltrate.

Treatment of oral burns due to chemical trauma principally requires clinically acumen and removal of the toxic agents. Most chemical burns are characterized by mild to moderate tissue damage that heals spontaneously within 7 to 14 days without scarring and requires only palliative and symptomatic treatment such as topical anaesthetic benzocaine ointment (Mucopain), Chlorhexidine gluconate gel. ${ }^{9,10}$ In instances of more severe tissue damage, non-potent topical corticosteroids (eg triamcinolone) in a protective vehicle of carboxymethylcellulose may be helpful. Lesions occurring after extensive exposure to strong caustic agents may require local debridement and antibiotic therapy.

\section{Conclusion}

Patients history plays the most important role to reach the diagnosis so it is crucial to obtain the detailed patient history.

\section{Conflict of Interest: None.}

\section{Reference}

1. Gandara-Rey JM, Diniz-Freitas M, Gandara-Vila P, Blanco-Carrion A, Garcia-Garcia A. Lesions of the oral mucosa in cocaine users who apply the drug topically. Med Oral 2002;7:103-07.

2. Blanksma CJ, Brand HS. Cocaine abuse: orofacial manifestations and implications for dental treatment. Int Dent J 2005;55:365-69.

3. Kapila YL, Kashani H. Cocaine-associated rapid gingival recession and dental erosion. A case report. $J$ Periodontol 1997;68:485-88.

4. Lai MW, Klein-Schwartz W, Rodgers GC, Abrams JY, Haber DA, Bronstein AC et al. 2005 Annual Report of the American Association of Poison Control Centers' national poisoning and exposure database. Clin Toxicol (Phila) 2006;44:803-932.

5. Murdoch-Kinch CA, Mallatt ME, Miles DA. Oral mucosal injury caused by denture cleanser tablets: a case report. Oral Surg Oral Med Oral Pathol Oral Radiol Endod 1995;80:756-58.

6. Varkey P, Tan NC, Chen HC. Corrosive injury of oral cavity-a rare presentation. J Plast Reconstr Aesthet Surg 2006;59:1110-13.

7. Sapir S, Bimstein E. Cholinsalicylate gel induced oral lesion: report of case. J Clin Pediatr Dent 2000;24:103-06.

8. Baruchin AM, Lusting JP, Nahlieli O. Burns of the oral mucosa. Report of 6 cases. J Craniomaxillofac Surg 1991;19:94-6.

9. Holmes RG, Chan DC, Singh BB. Chemical burn of the buccal mucosa. Am J Dent 2004;17:219-20

10. Smith C J. An approach to dealing with mucosal damage. J Am Dent Assoc 1991;122:73-4.

How to cite the article: Poswal A, Jain H., Garg B, Sharma P, Aspirin Induced intraoral Burn: A rare case report with emphasis on its diagnosis J Dent Specialities 2018;6(2):172-173. 